Volume 9, No.4, July - August 2020

International Journal of Advanced Trends in Computer Science and Engineering

Available Online at http://www.warse.org/IJATCSE/static/pdf/file/ijatcse184942020.pdf

https://doi.org/10.30534/ijatcse/2020/184942020

\title{
Bottle-SegreDuino: An Arduino Frequency-Based Bin for Tin Can and Plastic Bottle Segregation using an Inductive Proximity Effect
}

\author{
Jesusimo L. Dioses, Jr. \\ Isabela State University, Echague, Isabela, Philippines, jdiosesjr@gmail.com
}

\begin{abstract}
In the current scenario, waste disposal has become a major problem owing to increasing urbanization, industrial activities, and growth in the human population. The world's volume of solid waste produced is gradually increasing; inadequate recycling and improper disposal of solid waste is a source of water, land and air contamination, and presents risks to human health and the atmosphere. Currently, policy in all countries is working on innovative approaches to tackling the problems posed by solid waste management (SWM). Various methods have been developed and utilized for effective solid waste disposal and segregation. Through an inductive proximity sensor and ultrasonic proximity sensor, this paper aims to separate tin can from the plastic bottle. Ultrasonic proximity sensor transmits ultrasonic waves to sense target presence or absence. This is connected to the inductive proximity sensor which is connected to a microcontroller to separate metals from plastics to process the data of each object. The device includes an inductive proximity sensor that is used to detect metallic objects without any contact. When the object reaches the sensor, the current flow of induction decreases, particularly on metals, as it has higher frequencies than plastic. The study was conducted with a total evaluation accuracy of $94 \%$.
\end{abstract}

Key words: Arduino, Inductive Proximity, Plastic Bottle, Tin Can, Waste Segregation.

\section{INTRODUCTION}

Solid waste is what people throw away every day [1]. Full industrial waste originates from hazardous waste in agriculture, manufacturing, business, and urban waste [2]. Municipal Solid Waste (MSW) is the waste generated by the citizens in their homes, and where they function that is managed and regulated by municipal authorities such as communities or municipalities [3]. MSW includes all sorts of trash from the pulp, yard waste, bottles, outdated equipment, kitchen trash, discarded furniture, and everything citizens throw away at houses, schools, and companies [4]. Sustainable disposal of solid waste is a critical issue not just for developing countries but also for industrialized countries
[5]. Plastic waste, though, is quite problematic because of its non-biodegradability as a large component and part of urban solid waste which will, therefore, linger in the environment for a long period with all kinds of problems [6].

Waste segregation is necessary nowadays because the amount of solid waste produced every day in every residence is very troubling [7]. Solid waste is the trash the water cannot dissolve; thus, if not sufficiently filtered, they can be clogged in canals, or worse, they can float across the water sources [8]. Such toxic waste will also be recyclable when correctly processed and converted into modern consumer goods [9].

As a consequence of emerging technologies and shifting lifestyles, along with the growing urban population, significant quantities of waste are generated, involving various kinds of discarded materials [10]. When left unattended, organic waste can begin to break down by natural systems that trigger odors, attract, or feeding several insects and rodents that attract carriers of diseases that cause serious health problems [11]. Active management of solid wastes is required to address this issue. Waste is handled in the early days, using four simple methods, minimization of landfilling / dumping, recycling, and waste burning [12].

Solid waste segregation is one of the main building blocks of the SWM framework. Solid waste includes numerous items, such as metal parts; plastics, etc., all of which may be recycled to serve as input to certain methods [13]. Agricultural waste, for instance, may be used to generate biogas, such that the residue can be used as bio-fertilizers for the processing of metal parts. Plastic waste is resistant to degradation and can never be quickly dumped into the garbage or disposed of by burning because plastic waste is converted into fluorocarbon pollution through incineration which destroys the ozone layer [14]. Proper SWM needs the handling and isolation of solid waste.

The study built a device that would automatically segregate plastic bottles and tin cans. It differentiates metals from plastics based on the solid waste 's frequency. This immediately removes plastics from metal as it reaches the platform. This project can help consumers segregate waste, particularly plastics which, as of now, are the leading cause of flooding not only in the Philippines but also in other countries. 


\section{RELATED LITERATURE}

In [15], a Municipal Solid Waste (MSW) composting system has been suggested. Several waste segregation techniques, such as eddy current, magnetic separation, wet isolation, air characterization, etc. in which the separation of rubber, ferrous, glass, non-ferrous, and agricultural waste is proposed here. For this reason, using Trammel or Screen, the first waste is split into different sizes, and each waste dimension is treated separately. The paper suggests a mechanical device for all those items. Size segregation is primarily intended to encourage further separation in a composting system. More classification of objects on a comparable size is also easier for either humans or equipment because small things are not covered under big ones.

In [16], an efficient segregation method for distinguishing various types of plastics has been developed. The techniques of multivariate analysis \& NIR spectroscopy have been used, developed, and extended to separate the plastics using the Raspberry $\mathrm{Pi}$ system. Python was used to develop computational algorithms and GUI. This system can differentiate between 5 different kinds of plastics.

In [17], informal handling of solid waste using a mechanical isolation system and an optical sensor has been proposed. The color, form, and scale of the waste are used in this waste separation process. The motorized sorter is a compressed air nozzle operated by a microcontroller; The target particles detected by the sensor were blasted off from the key waste stream.

In [18], the X-ray fluorescence approach for isolation of materials has been suggested. This approach measures the basic structure of the X-ray fluorescence of the various materials. Objects with different elements are observed based on this analysis and may be isolated from the stream of material. The sorting systems can be used to handle products such as bottles, ceramics, stones, minerals, and plastics.

In [19], has proposed an image processing device for the automatic separation of medical waste which also reduces the possibility of contamination during manual diagnosis. The programmable Logic System was used to isolate the metal from waste products [20]. Within this system, the waste will be fed onto the conveyor belt where metal ions will be detected by clamped metal detectors. The metal is extracted from the waste by a robotic arm and deposited in a bin.

\section{METHODOLOGY AND RESULTS}

\subsection{Methodology}

As the material is dropped on the system, the Ultrasonic proximity sensor transmits ultrasonic waves to detect the presence of or absence of the target. It is connected to the inductive proximity sensor, which differentiates metals from plastics is connected to a microcontroller to process the data of each material as shown in figure 1 . The device incorporates an inductive proximity sensor used to detect metallic items without touching, as seen in Figures 2 and 3. As the target approaches the sensor, the induction current flow increases, especially on metals, because it has higher frequencies than plastic.

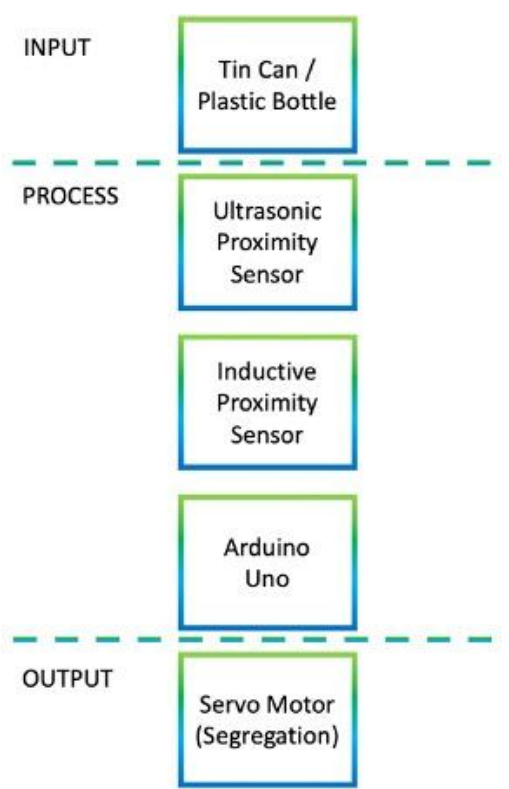

Figure 1: The methodology of Segregation.

The Arduino Board used several applications and research in conducting the various approaches to segregation. This is one of the freeware electronic kits which works with easy-to-use hardware and software as of today. [21], [22], [23], [24], [25], and [26] used the power of Arduino as microcontroller.

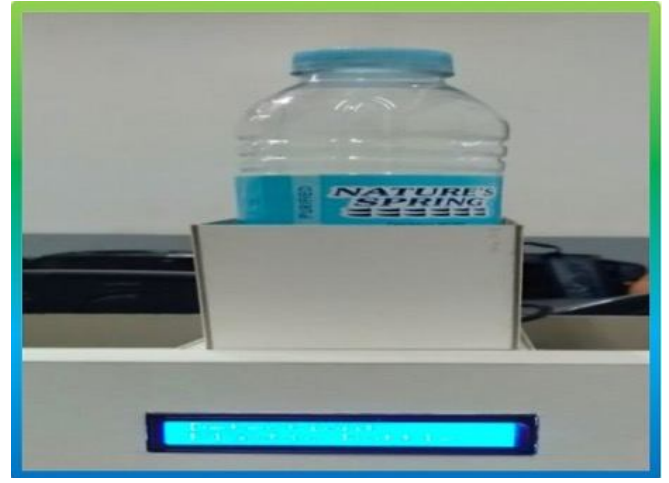

Figure 2: Prototype with Plastic Bottle.

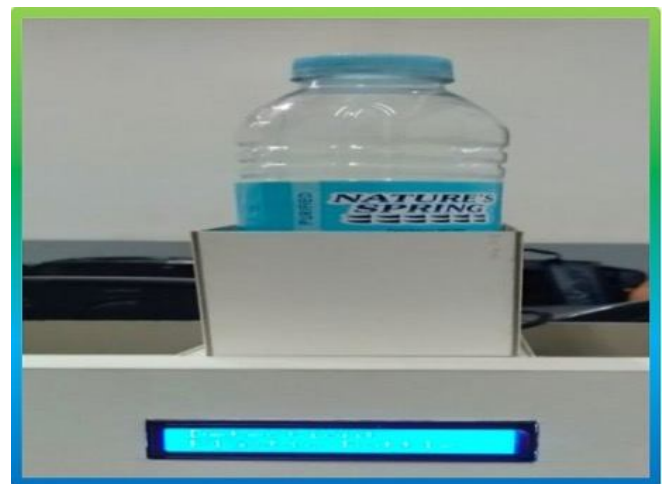

Figure 3: Prototype with Tin Can. 
The study used an oscilloscope to display the peak voltage produced by the instruments, to establish the reference level of the ultrasonic proximity sensor and the inductive proximity sensor. The study experimented to decide what amount of reference value will provide a stronger response. The efficiency of the device is affected by changing the reference value. The data obtained show that the device is in a stronger response with the ultrasonic sensor's value reference point from $<=8$ distance for no material sense and up to $>=10$ for measuring whether it is a tin can. Table 1 was used in the analysis as the varying susceptibility of metals to space. The sensor output goes through the microcontroller.

Table 1: Sensitivity of Metals

\begin{tabular}{cc}
\hline \hline Sensitivity when different metrls are present. $\mathrm{Sn}=$ operating distance. \\
\hline \hline Fe37 (Iron) & $1 \times \mathrm{Sn}$ \\
Stainless steel & $0.9 \times \mathrm{Sn}$ \\
Brass - Bronze & $0.5 \times \mathrm{Sn}$ \\
Aluminum & $0.4 \times \mathrm{Sn}$ \\
Cogrser & $0.4 \times \mathrm{Sin}$ \\
\hline \hline
\end{tabular}

\subsection{Results}

There were 30 plastic bottle samples and 30 tin-cans samples used in the study. Ten trials were done per experiment. Tables 2 and 3 below show the summary of the results of the system's overall test using plastic and tin containers.

Table 2: Data and Results of Plastic Bottles

\begin{aligned} & \hline \multicolumn{1}{c}{ Plastic Buttles } Accuracy uf Study per 10 Trials (\%) \\ & \hline Sprite 100 \\ & Foyal 90 \\ & Coke 90 \\ & Pepsi 90 \\ & Nestea 100 \\ & Summit 100 \\ & Funily Alcohol 60 \\ & Calamansi 90 \\ & Cobra 90 \\ & Lipion 90 \\ & \hline Mean.Aworage \\ & \hline \hline\end{aligned}

Table 3: Data AND Results of Tin CAN

\begin{aligned} & \hline \multicolumn{1}{c}{ Tin Cans } Accuracy of Study per 10 Trials (\%) \\ & \hline Sprite 100 \\ & San Mariano 100 \\ & Coke 100 \\ & 555 Tuna 100 \\ & Ligo 100 \\ & 7up 90 \\ & Del Monte 90 \\ & Young's Town 100 \\ & Sarsi 100 \\ & Root Beer 100 \\ & \hline Mean Average \\ & \hline \hline\end{aligned}

Table 2 shows the study's overall system accuracy test, the system was tested with various plastic containers and dropped into the system one by one. The system was tested using 10 trials per sample. The accuracy of the plastic bottles produced
$90 \%$. For tin containers, it produced a $98 \%$ mean average accuracy.

\section{CONCLUSION AND FUTURE WORKS}

The plastic bottle and tin can segregation using Arduino Uno, through the inductive proximity sensor, it separates the tin cans and the plastic bottles. As the tin cans and plastic bottles hit the platforms, the sensor will automatically separate plastics from metal. The study proved $90 \%$ and $98 \%$ testing accuracy for plastic bottles and tin cans respectively. Overall, the accuracy of the whole system produced $94 \%$. In conclusion, the aims of this project are achieved. Effective implementation of plastic bottles and faster tin cans segregator is completed. The door will open and shut for the wastes based on the feedback from the sensor.

The study is intended for plastic bottles and tin cans only. For more development of this study, further solid waste products can be combined for segregation. Through this initiative, various customers will help to reduce the recycling period and waste segregation. Recreational products can be used again for this solid waste materials.

\section{ACKNOWLEDGEMENT}

The researcher would like to convey his appreciation to the Isabela State University - Echague Campus for the support and the encouragement.

\section{REFERENCES}

1. J. Peirce, R. Weiner and P. Vesilind, Solid Waste Disposal, Environmental Pollution and Control, pp. 167-176, 1998. doi: 10.1016/b978-075069899-3/50014-6

2. J. Szczepańska and I. Twardowska, Principles of vadose and saturated zones monitoring in solid waste sites exemplified in mining waste dumps, Solid Waste: Assessment, Monitoring and Remediation, pp. 551-575, 2004. doi: 10.1016/s0713-2743(04)80022-9

3. M. Rao, R. Sultana and S. Kota, Municipal Solid Waste, Solid and Hazardous Waste Management, pp. 3-120, 2017. doi: 10.1016/b978-0-12-809734-2.00002-x

4. S. El-Haggar, Sustainability of Agricultural and Rural Waste Management, Sustainable Industrial Design and Waste Management, pp. 223-260, 2007. doi: 10.1016/b978-012373623-9/50009-5

5. A. Diaz-Barriga-Fernandez, J. Santibañez-Aguilar, J. Betzabe González-Campos, F. Nápoles-Rivera, J. Ponce-Ortega and M. El-Halwagi, Strategic planning for managing municipal solid wastes with consideration of multiple stakeholders, 13th International Symposium on Process Systems Engineering (PSE 2018), pp. 1597-1602, 2018. doi: 10.1016/b978-0-444-64241-7.50261-5

6. L. Mai, L. Bao, C. Wong and E. Zeng, Microplastics in the Terrestrial Environment, Microplastic Contamination in Aquatic Environments, pp. 365-378, 2018. doi: 10.1016/b978-0-12-813747-5.00012-6 
7. N. Malik, S. Abdullah and L. Manaf, Community Participation on Solid Waste Segregation Through Recycling Programmes in Putrajaya, Procedia Environmental Sciences, vol. 30, pp. 10-14, 2015. doi: 10.1016/j.proenv.2015.10.002

8. C. Chaidez, M. Soto and M. Jimenez, Water: waste, recycling and irrigation in fresh produce processing, Global Safety of Fresh Produce, pp. 119-132, 2014. doi: 10.1533/9781782420279.2.119

9. W. Li, G. Sheng and H. Yu, Electricity Generation from Food Industry Wastewater Using Microbial Fuel Cell Technology, Food Industry Wastes, pp. 249-261, 2013. doi: 10.1016/b978-0-12-391921-2.00014-7

10. L. Rigamonti, M. Grosso, J. Møller, V. Martinez Sanchez, S. Magnani and T. Christensen, Environmental evaluation of plastic waste management scenarios, Resources, Conservation and Recycling, vol. 85, pp. 42-53, 2014. doi: 10.1016/j.resconrec.2013.12.012

11. I. Muralikrishna and V. Manickam, Solid Waste Management, Environmental Management, pp. 431-462, 2017. doi: 10.1016/b978-0-12-811989-1.00016-6

12. H. Abdel-Shafy and M. Mansour, Solid waste issue: Sources, composition, disposal, recycling, and valorization, Egyptian Journal of Petroleum, vol. 27, no. 4, pp. 1275-1290, 2018. doi: 10.1016/j.ejpe.2018.07.003

13. S. Xiao, H. Dong, Y. Geng and M. Brander, An overview of China's recyclable waste recycling and recommendations for integrated solutions, Resources, Conservation and Recycling, vol. 134, pp. 112-120, 2018. doi: 10.1016/j.resconrec.2018.02.032

14. G. Faraca and T. Astrup, Plastic waste from recycling centres: Characterisation and evaluation of plastic recyclability, Waste Management, vol. 95, pp. 388-398, 2019. doi: 10.1016/j.wasman.2019.06.038

15. T. Richard, Municipal solid waste composting: Physical and biological processing, Biomass and Bioenergy, vol. 3, no. 3-4, pp. 163-180, 1992.

doi: 10.1016/0961-9534(92)90024-k

16. L. Madan Kumar, B. Pavan, P. Kalyan, Nirmal Savio Paul, R. Prakruth and T. Chinnu, Design of an embedded based control system for efficient sorting of waste plastics using Near Infrared Spectroscopy, 2014 IEEE International Conference on Electronics, Computing and Communication Technologies (CONECCT), 2014. doi: 10.1109/conecct.2014.6740338

17. J. Huang, T. Pretz and Z. Bian, Intelligent solid waste processing using optical sensorbased sorting technology, 2010 3rd International Congress on Image and Signal Processing, 2010. doi: 10.1109/cisp.2010.5647729

18. M. Kern, L. Tusa, T. Leißner, K. van den Boogaart and J. Gutzmer, Optimal sensor selection for sensor-based sorting based on automated mineralogy data, Journal of Cleaner Production, vol. 234, pp. 1144-1152, 2019. doi: 10.1016/j.jclepro.2019.06.259
19. M. Nagori, R. S. Jachak and P. P. Chaudhari, A framework for segregating solid waste by employing the technique of image annotation,2019 Second International Conference on Advanced Computational and Communication Paradigms (ICACCP), Gangtok, India, 2019, pp. 1-6, doi: 10.1109/ICACCP.2019.8882932.

20. M. Jayson, S. Hiremath and L. H.R., SmartBin-Automatic waste segregation and collection, 2018 Second International Conference on Advances in Electronics, Computers and Communications (ICAECC), Bangalore, 2018, pp. 1-4, doi: 10.1109/ICAECC.2018.8479531.

21. A. Alon and J. Susa, Wireless Hand Gesture Recognition for an Automatic Fan Speed Control System: Rule-Based Approach, 2020 16th IEEE International Colloquium on Signal Processing \& Its Applications (CSPA), 2020. doi: 10.1109/cspa48992.2020.9068687

22. A. Alon, SmaCk: Smart Knock Security Drawer Based on Knock-Pattern using Piezo-electric Effect, International Journal of Emerging Trends in Engineering Research, vol. 8, no. 2, pp. 339-343, 2020. doi: 10.30534/ijeter/2020/16822020

23. J. L. Dioses Jr., AndroiDuino-Fan: A Speech Recognition Fan-Speed ControlSystem utilizing Filipino Voice Commands, International Journal of Advanced Trends in Computer Science and Engineering, vol. 9, no. 3, pp. 3042-3047, 2020. doi: $10.30534 /$ ijatcse/2020/84932020

24. C. Casuat, A. Alon, J. Dioses Jr., R. Dellosa and R. Diamante,RFID Controlled "GG" Pieces Ranking Detection with Watch-Dog EnableInternational Journal of Advanced Trends in Computer Science and Engineering, vol. 9, no. 1.3, pp. 274-279, 2020. doi: 10.30534/ijatcse/2020/4191.32020

25. J. Mindoro, Drowsy or Not? Early Drowsiness Detection utilizing Arduino Based on Electroencephalogram (EEG) NeuroSignal, International Journal of Advanced Trends in Computer Science and Engineering, vol. 9, no. 2, pp. 2221-2226, 2020. doi: 10.30534/ijatcse/2020/200922020

26. C. Casuat, Biofuz: A Takagi Sugeno Fuzzy Expert-Based Rice Straw Enhanced Decomposition System, International Journal of Advanced Trends in Computer Science and Engineering, vol. 9, no. 2, pp. 2168-2172, 2020. doi: 10.30534/ijatcse/2020/192922020 